\title{
O Encontro Nacional de Arquitectos: Tomar consciência da sociedade
}

The National Meeting of Architects: Creating Awareness of Society Les rencontres nationales d'architectes : prendre conscience de la société

João Afonso

\section{OpenEdition}

\section{Journals}

Edição electrónica

URL: http://journals.openedition.org/rccs/3729

DOI: $10.4000 /$ rccs.3729

ISSN: $2182-7435$

\section{Editora}

Centro de Estudos Sociais da Universidade de Coimbra

Edição impressa

Data de publição: 1 Dezembro 2010

Paginação: 27-39

ISSN: 0254-1106

\section{Refêrencia eletrónica}

João Afonso, « O Encontro Nacional de Arquitectos: Tomar consciência da sociedade », Revista Crítica de Ciências Sociais [Online], 91 | 2010, colocado online no dia 16 outubro 2012, criado a 19 abril 2019. URL : http://journals.openedition.org/rccs/3729; DOI : 10.4000/rccs.3729 


\title{
JOÃO AFONSO
}

\section{O Encontro Nacional de Arquitectos: Tomar consciência da sociedade*}

\begin{abstract}
Este texto propõe uma leitura do Encontro Nacional dos Arquitectos de 1969, partindo da análise da documentação (convocatória, comunicados, comunicações, conclusões temáticas, moção final e outros documentos), de artigos publicados e depoimentos recolhidos recentemente junto de alguns participantes, tendo em conta a situação política, social e profissional dessa época.

Apresenta-se uma abordagem em cinco aspectos que se consideram relevantes para a compreensão do Encontro como revelação de uma alteração social e política no âmbito da profissão - as reuniões plenárias dos arquitectos que a antecederam, a relação com as eleições para a Assembleia Nacional de Outubro de 1969, a situação do Sindicato Nacional dos Arquitectos no final dos anos 60, a importância dos conteúdos em debate na caracterização da mudança das preocupações profissionais e o "desencontro geracional".
\end{abstract}

Palavras-chave: arquitectos portugueses; Encontro Nacional de Arquitectos (ENA); I Congresso Nacional de Arquitectura; 1969.

\section{Introdução}

O "Encontro Nacional dos Arquitectos de 1969" [Encontro] foi a quarta reunião, com carácter plenário, dos arquitectos portugueses e última antes do 25 de Abril, realizando-se mês e meio depois das eleições legislativas de 1969. O Encontro marca o fim de um ciclo e o início de um novo e, para além do seu significado intrínseco, expressa também o modo como um grupo profissional específico - o dos arquitectos - pode consubstanciar o reflexo de uma sociedade em mudança.

$\mathrm{Na}$ ausência de reflexões críticas sobre o Encontro, a "memória” dos participantes subsiste como suporte para justificar a sua relevância na história da arquitectura portuguesa. Não tendo sido publicadas conclusões e teses,

* Este texto enquadra-se na investigação para a tese de doutoramento "Um contributo para a construção da democracia. Uma leitura da arquitectura em Portugal entre 1948 e 1974", coordenada pelo Professor Arquitecto Alexandre Alves Costa e pelo Professor Doutor Arquitecto José António Bandeirinha, com o apoio da Fundação para a Ciência e Tecnologia. 
mas apenas uma síntese do sucedido elaborada logo após a sua realização, esses relatos e os poucos registos da reunião publicados à época são insuficientes para entender a sua real importância e significado.

O presente texto propõe uma reflexão sobre o Encontro através de cinco enfoques com os quais este se relaciona: as reuniões de arquitectos; as eleições legislativas de 1969; o papel do Sindicato Nacional dos Arquitectos [Sindicato]; os conteúdos do debate; e os participantes. ${ }^{1}$ É a partir da análise desses temas que, propondo uma leitura do Encontro, se conclui sobre a sua relevância na história da arquitectura portuguesa, mas também sobre o momento político-social que a sociedade portuguesa atravessava.

O objectivo do texto é demonstrar como os arquitectos foram tomando consciência do seu papel político e como o debate colectivo assume um papel fulcral nessa transformação. Ou seja, estes espaços de debate - Congresso, reuniões e Encontro - são instrumentos de reflexão e crítica sobre a arquitectura e a profissão, mas também sobre a própria sociedade. Por fim, pretende-se questionar qual a importância deste Encontro, como momento de charneira, para o debate da profissão até ao presente, quando a questão "política” se enuncia como argumento para justificação da prática arquitectónica.

\section{Congresso e reuniões: o papel de uma profissão na sociedade}

O I Congresso Nacional de Arquitectura [I Congresso], em 1948, foi promovido e organizado pelo Sindicato, mas despoletado pelo Ministro das Obras Públicas, José Ulrich, que sugeriu aos arquitectos e engenheiros organizarem os respectivos congressos profissionais na ocasião da apresentação da "Exposição dos 15 Anos de Obras Públicas - 1932-1947”, iniciativa de consagração da política de equipamentos e infraestruturas do Estado Novo (Ribeiro, 2008: 25).

Enquanto no II Congresso Nacional dos Engenheiros, realizado em paralelo com o dos arquitectos, foram apresentadas comunicações sobre aspectos técnicos e trabalhos já executados ou projectados, destacando o contributo da engenharia na obra do Estado Novo (Rodrigues e Pereira, 1996: 186-188), os arquitectos aproveitaram a oportunidade de as comunicações não terem sido submetidas a censura prévia para reclamarem a sua autonomia profissional e criticarem a imposição de uma linguagem nacional da arquitectura. Nas teses individuais e nas conclusões aprovadas, com inúmeras críticas e propostas ao poder político, o I Congresso divergiu do tom celebrativo que o governo esperava unânime.

\footnotetext{
${ }^{1}$ No âmbito do trabalho de investigação foram efectuadas entrevistas sobre a actuação dos arquitectos a nível individual e colectivo entre 1948 a 1974, sendo que alguns dos participantes no Encontro, nomeadamente Nuno Teotónio Pereira, Raul Hestnes Ferreira, Manuel Vicente e Manuel Nicolau Brandão, o classificaram como um acontecimento da maior relevância neste período.
} 
Em 1957, após a tentativa de promoção de um II Congresso que não obteve o necessário apoio do Governo, a direcção do Sindicato convoca a "I Reunião de Arquitectos" [I Reunião] alterando a designação e o modelo de encontro - menos dias e debate a partir de textos propostos pela comissão organizadora (Direcção, 1957).

O tema geral da I Reunião foi "Problemas do exercício da profissão do arquitecto" mas os objectivos propostos transcendiam as questões disciplinares, pois o que se pretendia era "[...]levar a Classe a tomar consciência, como Classe, de certos assuntos que lhe dizem respeito e estabelecer as bases dum trabalho ulterior eficiente para os poder estudar e sanear." [sublinhado no original]. Na segunda reunião magna dos arquitectos pretendia-se, mais do que discutir os textos apresentados ${ }^{2}$ e alcançar conclusões, aproximar os arquitectos e criar uma identidade colectiva.

O discurso técnico, especializado e disciplinar dominou as reuniões profissionais ao longo dos anos 60 , consonante com a política de desenvolvimento socioeconómico em implementação pelo regime, facto a que os arquitectos não estiveram alheados (Brito e Rollo: 1996).

Em 1966 realiza-se a "II Reunião Geral de Arquitectos" cujo objectivo era a estruturação da profissão. A ausência de um título que a enquadre é também reflexo de um rigor tecnocrático isento que se pretendia incutir no debate dos temas ${ }^{3}$ (Direcção, 1966). O terceiro grande encontro de arquitectos foi totalmente centrado no exercício da profissão, na tentativa de criar as condições ideais e necessárias para que os arquitectos cumprissem a sua função para com a sociedade. Foram constituídas, com muitos meses de antecedência, equipas de trabalho com arquitectos de Lisboa e Porto para preparação da reunião e dos documentos, facto revelador da estruturação associativa já alcançada. Os documentos orientadores da prática foram debatidos e aceites na generalidade.

O "Colóquio sobre política de habitação", organizado pelo Ministério das Obras Públicas e não pelo Sindicato, em Julho de 1969, foi o debate tecnocrático do âmbito da arquitectura com mais relevantes consequências (Bandeirinha, 2007: 68-84). Alguns meses antes do Encontro, o descontentamento que este tipo de encontro gerava está patente na denúncia de Nuno Teotónio Pereira, ${ }^{4}$ para quem a liberdade permitida aos especialistas pelo

\footnotetext{
2 Textos base da I Reunião de Arquitectos: "A elevação do nível profissional”; "Relações com as entidades a que se prestam, ou de quem dependem, os serviços profissionais".

3 Temas da II Reunião Geral de Arquitectos "Orgânica Sindical", "Secção Portuguesa da União Internacional dos Arquitectos", "Previdência Social" e "Regulamentos da actividade profissional". ${ }^{4}$ Nuno Teotónio Pereira participa no Colóquio sobre política de habitação como arquitecto consultor da Federação das Caixas de Previdência mas pouco depois publica clandestinamente o texto referido.
} 
regime era uma "Nova forma, menos brutal e mais insidiosa, de manter a opinião pública passiva” (Pereira, 1996: 101).

Os temas e debates nas reuniões de arquitectos são demonstrativos da evolução do seu pensamento, da necessidade da afirmação disciplinar perante a sociedade em 1948, passando pela identificação do grupo em 1957, até ao debate definidor das suas regras para servir a sociedade em 1966. No fundo, um discurso que se inicia na identidade, passando para a afirmação do colectivo, para depois se estabelecer a forma de agir. Foram estes debates que criaram as condições para o Encontro de 1969; a profissão já não estava em questão, mas sim a sociedade na qual queriam intervir.

\section{O Encontro e as eleições legislativas de 1969}

A 6 de Novembro de 1969, no rescaldo das eleições legislativas ocorridas a 26 de Outubro, é enviado aos membros do Sindicato um memorando convocando o "Encontro Nacional de Arquitectos" para os dias 6, 7 e 8 de Dezembro desse ano na Sociedade Nacional de Belas Artes, em Lisboa (Comissão Organizadora, 1969a).

As eleições legislativas de 1969 foram as primeiras após a indigitação de Marcelo Caetano como Presidente do Conselho, nomeação na qual muitos depositaram a esperança de mudança do regime. $\mathrm{O}$ afastamento do Governo desde 1958 e a demissão do cargo de Reitor da Universidade de Lisboa, em protesto pela acção da polícia durante os protestos estudantis de 1962, distanciando-se de Salazar, permitiu a Marcelo Caetano assumir o poder com uma aura de liberal (Raby, 1988: 261).

As reformas implementadas ao longo do primeiro ano de mandato, nomeadamente no que refere à censura, à polícia política, às eleições, aos sindicatos, ${ }^{5}$ assim como a alguns gestos políticos de carácter simbólico - o regresso do exílio de Mário Soares e do Bispo do Porto, António Ferreira Gomes - mais do que uma reforma efectiva, criaram a convicção de que a proclamada "mudança na continuidade" seria possível. A forma como decorreu o processo eleitoral pôs fim a essa esperança.

A oposição levou as suas candidaturas até às urnas, ao contrário das anteriores eleições legislativas de 1961 e 1965, apesar de todas as dificuldades desde logo a não actualização dos cadernos eleitorais e a impossibilidade de acesso a estes. Na maioria dos distritos do país, a oposição concorreu em lista única pela Comissão Democrática Eleitoral [CDE], que reunia comunistas,

\footnotetext{
${ }^{5}$ Decreto-Lei n. ${ }^{\circ} 49058$ de 14 de Junho de 1969 , alterou a lei sindical nomeadamente no que refere à liberdade de eleição para os corpos sociais dos organismos corporativos, pondo fim ao controlo prévio pela tutela.
} 
socialistas, católicos progressistas e liberais. Mas surge dividida em três distritos do país - Braga, Lisboa e Porto - reflectindo a tensão existente entre comunistas e socialistas, nomeadamente no que refere à questão colonial, tendo os últimos concorrido sob a denominação de Comissão Eleitoral de Unidade Democrática [CEUD] (Cervelló, 2010: 99).

A divisão na oposição transparecera no II Congresso Republicano, em Maio desse ano na cidade de Aveiro, com divergência de posições entre as tendências já referidas, assim como entre outros grupos, desde os históricos republicanos aos novos grupos de extrema-esquerda. O final da década é marcado por uma "esquerdização global do oposicionismo", por um lado com o surgir de grupos de inspiração marxista-leninista, maoistas de inspiração comunista chinesa e ainda trotsquistas, que puseram em causa o discurso e a prática da oposição tradicional; por outro lado, os "católicos progressistas" que, baseados numa leitura "esquerdizante" do Concílio Vaticano II, vão contestar social e politicamente o regime. Estes grupos tiveram em comum uma nova forma de actuar e a exigência do fim da guerra colonial (Rosas, 2004: 118-120).

As candidaturas oposicionistas mobilizam inúmeros arquitectos, tendo alguns assumido posições de protagonismo, como Nuno Teotónio Pereira, ${ }^{6}$ que se apresentou como candidato pela C.D.E. ${ }^{7}$ ao distrito de Portalegre, e Francisco Keil do Amaral, ${ }^{8}$ como membro da C.E.U.D. (Soares, 1999: 140).

A relativa liberdade que se viveu no período que antecedeu as eleições permitiu a realização de debates em todo o país. O entusiasmo que rodeou o período da campanha eleitoral levou os promotores do Encontro a considerar que a sua abrangência tinha dado lugar a "um largo movimento de consciência política” (Comissão Organizadora, 1969a: 1) em torno de problemas como a habitação e o desenvolvimento urbano, temas recorrentes do debate disciplinar. É nesse contexto que, "preocupados com a responsabilidade social da sua actividade", afirmam ter efectuado diversas reuniões para reflectir sobre qual o contributo que os arquitectos poderiam dar para a consciencialização das populações e, perante o interesse suscitado, decidiram promover o Encontro para permitir a participação de todos os arquitectos.

\footnotetext{
${ }^{6}$ Arquitecto, católico progressista, fundador do Movimento de Renovação de Arte Religiosa, Prémio Valmor e Prémio Gulbenkian de Arquitectura.

7 Entrevista de Nuno Teotónio Pereira a João Afonso sobre o Encontro Nacional de Arquitectos, em 15 de Janeiro de 2010.

${ }^{8}$ Arquitecto, foi Presidente do Sindicato, tendo sido impedido de terminar o mandato em 1949 por despacho do Ministro das Corporações.
} 


\section{O Encontro e o Sindicato Nacional dos Arquitectos}

A organização do Encontro foi da iniciativa de uma comissão organizadora ou preparatória ${ }^{9}$ que contou com a colaboração do Sindicato, ao contrário das anteriores reuniões. Mas a razão desse afastamento não é explicada na "Circular 22/36" (Direcção, 1969da Direcção do Sindicato, de 20 de Novembro, apesar da aparente simplicidade do "dilema da participação activa ou não participação” antes anunciado (Torres et al., 1969: 1).

Os corpos sociais do Sindicato em exercício no final de 1969 eram os do triénio 1966/1968, cuja eleição ocorreu em Março de 1966, mas cuja tomada de posse teve lugar em Janeiro de $1969^{10}$ (S.N.A, 1934: 36-37). Só no Verão de 1968 o Governo homologou parcialmente os resultados da eleição, impedindo de tomar posse dois dos quatro membros da Direcção e três dos cinco elementos do Conselho Disciplinar, viabilizando o mínimo legal para a sua constituição, mas, dessa forma, impossibilitando qualquer tipo de actividade para lá da gestão corrente (Guimarães et al., 1969: 6). Artur Pires Martins e José Leopoldo Ramalho Leal tomam posse constituindo a direcção do Sindicato; Mário Jorge Bruxelas e António Pinto de Freitas foram impedidos de assumir o cargo porque estavam desde 1963 identificados pela PIDE como pertencentes ao núcleo comunista de arquitectos (Pimentel, 2007: 175-176).

A direcção do Sindicato de 1966/68 iniciou o seu mandato quando já devia ter terminado, tendo promovido de imediato o processo de eleição para o mandato 1969/1971, organizando sessões nas quais se definiram equipas para assegurar a actividade imediata, objectivos para o triénio seguinte e os futuros órgãos sociais (Guimarães et al., 1969: 8).

As novas eleiçõos para o Sindicato ocorreram a 17 de Março de 1969, mas a sua homologação voltou a tardar, dando azo à continuação das reuniões que tinham sido lançadas para "consciencialização e dinamização da Classe, em volta dos seus problemas mais prementes.” Será aos participantes destas reuniões que a Direcção do Sindicato sugeriu a organização do Encontro para dar continuidade ao debate surgido no âmbito da campanha para as eleições legislativas (Direcção, 1969).

A Direcção do Sindicato declara não poder participar activamente no Encontro (Direcção, 1969: 1), mas a comunhão de objectivos é expressa ao assumir legitimar as decisões que fossem tomadas. Se alguma dúvida

\footnotetext{
9 A comissão preparatória do Encontro não surge identificada no anúncio enviado a 6 de Novembro de 1969 e nos comunicados seguintes vêm identificados diferentes grupos de trabalho, com constituições distintas nos dois documentos, pelo que se conclui que a comissão preparatória não tinha uma constituição formal.

$1031^{\circ}$ Auto de Posse dos Corpos Sociais do Sindicato Nacional dos Arquitectos.
} 
pudesse subsistir sobre o envolvimento do Sindicato, basta analisar quem eram os membros dos Grupos de Trabalho para ela se desvanecer, pois dos dez eleitos em funções cinco estão envolvidos nos trabalhos ${ }^{11}$ e dos catorze eleitos em Março desse ano nove participam activamente no Encontro (S.N.A., 1934: 36-39).

\section{5. "Encontro - uma etapa de um percurso; momento de reflexão e crítica":12 conteúdos do debate}

O Encontro foi apresentado pela Comissão Organizadora com dois grandes objectivos: "a) uma tomada de consciência do papel do arquitecto na sociedade portuguesa actual; b) estudar as formas de intervenção no processo de esclarecimento e discussão públicas agora iniciado;" (Comissão Organizadora, 1969a: 1). Estes objectivos só seriam concretizados e consequentes se fosse assegurada a participação na preparação e no Encontro de arquitectos, estagiários, estudantes de arquitectura e profissionais afins. Do Encontro, explicitavam, pretendia-se debate e textos conclusivos não definitivos.

O programa de trabalhos propunha uma intensa agenda de sessões, intercalando trabalho em paralelo dos diversos grupos temáticos com plenários e alguns momentos de convívio. Nas primeiras sessões debatiam-se os documentos distribuídos antecipadamente e nas plenárias as conclusões que sucessivamente se iam alcançando; um modelo que se constata não ter funcionado.

As sessões de trabalho em grupo organizaram-se em torno dos temas anunciados - "Sindicalismo", "Política do Solo", "A repercussão na actividade do arquitecto das actuais estruturas da sociedade portuguesa e a sua intervenção nessas estruturas", "Participação popular e trabalho do arquitecto no desenvolvimento urbano", aos quais se acrescentou "A comunicação como contestação". O tema "Arquitectura e Burocracia" foi anunciado, mas por sugestão dos proponentes acabou integrado no tema "Sindicalismo".

Foram doze os documentos ${ }^{13}$ colocados a debate, apresentando reflexões e propostas dos seus autores, à semelhança do ocorrido no I Congresso e

\footnotetext{
${ }^{11}$ Mas se considerarmos que entretanto Carlos Ramos já falecera e outros três não o fizeram por residirem no Porto, então apenas um eleito do mandato 1967/1968 não participa nos Grupos de Trabalho.

12 Título que surge na folha de rosto da documentação entregue no primeiro dia do Encontro.

13 "Comunicação lida durante o Encontro promovido pela SPUIA em Junho de 1969, sobre o futuro da formação do arquitecto", Carlos Roxo; "Participação popular e trabalho do arquitecto", Nuno Teotónio Pereira; "Participação leiga e trabalho do arquitecto no desenvolvimento urbano", Pedro Vieira Almeida; "Participação popular e trabalho do arquitecto no desenvolvimento urbano", Romeu Pinto da Silva; "Participação popular e trabalho do arquitecto no desenvolvimento urbano", Elias Cachado Rodrigues, Júlio Zamith Carrilho, Eduardo Alves Martins; "Participação popular e trabalho do arquitecto no desenvolvimento urbano", Arnaldo Grilo, Manuel Felizardo, Maria Augusta Negreiros, Miguel Osório de Aragão, Nuno Teotónio Pereira,
} 
ao contrário das reuniões posteriores, em que os documentos debatidos apresentavam uma posição discutida e consensualizada antecipadamente. Os textos não procuravam representar uma opinião de classe, propor objectivos ou medidas a concretizar; pelo contrário, pretendiam contribuir para o debate, ou seja, "Estabelecer a polémica propondo algumas bases à reflexão" (Martins, 1969: 1).

Os textos têm em comum a crítica à situação social e política portuguesa, o desinteresse pelas questões disciplinares e organizativas e, ainda, a vontade de actuar politicamente, mas como arquitectos. O cerne da discussão não era a arquitectura ou as condições de exercício profissional. Os arquitectos queriam compreender a sociedade, procurar novas formas de nela intervir e, no limite, contribuir para a "a abolição das actuais estruturas político-económicas” (Pereira, 1969: 4).

As conclusões de cada grupo de trabalho expressam o resultado do debate, mas também a forma como ele decorreu, transparecendo um maior consenso quando se aproximam das ideias dos textos de base ou um maior conflito quando evitam qualquer proposta apresentada.

A moção final do Encontro foi uma desilusão para a Comissão Organizadora, cuja expectativa era "a produção efectiva de trabalho" (Comissão Organizadora, 1969a: 2), pois apenas foi aprovado a "continuação do movimento que deu lugar a este Encontro Nacional de Arquitectos” (Comissão Organizadora, 1969b: 4). Mas para muitos participantes terá sido o resultado desejado porque "no final aplaudiu-se a ausência de conclusões", conforme descreve Raul Hestnes Ferreira (apud Duarte, 1969: 203).

As conclusões finais do Encontro estão aquém das ideias colocadas a debate; são em comparação menos acutilantes e porventura mais concomitantes com o sistema político vigente. Mas, no entanto, é assumida a inquietação e denunciada a situação, intuindo-se a vontade da sua transformação como até então não se fizera colectivamente.

Para Carlos Duarte, a arquitectura foi encarada como um instrumento de intervenção e não o fulcro da discussão, num debate que raramente se debruçou sobre temas da própria disciplina, verificando-se uma evolução do "pensamento arquitectónico, em busca de mais amplas formas de integração social" (Duarte, 2006: 23).

Pedro Vieira de Almeida; "O arquitecto e a burocracia”, Alves Martins, António Portugal, Carlos de Almeida, Plácido Santos, Rogério Alvarez, Vaz Cunha; "O SNA ou uma associação livre de arquitectos", Artur Pires Martins, Carlos Roxo, Leopoldo de Almeida, Manuel Moreira; "Políticas de solos e actividade do arquitecto", Francisco Silva Dias e Júlio Saint-Maurice; "A repercussão na actividade do arquitecto das actuais estruturas da sociedade portuguesa e a sua intervenção nessas estruturas", Luís Vassalo Rosa; "Arquitectura e sociedade portuguesa", Nuno Portas; "A comunicação como contestação", Alberto Oliveira e Manuel Vicente. 


\section{Os participantes e o seu desencontro}

"Houve Encontro, apesar do desencontro", é dito em tom de desabafo por Carlos Roxo (apud Duarte, 1969: 203), ao constatar que os trabalhos do Encontro cumpriram o proposto pela Comissão Organizadora, embora não tenham decorrido como esperavam. É o relato desse desencontro que marca a memória desses dias, "Não somos amigos por sermos arquitectos" diz por sua vez Manuel Vicente (apud Duarte, 1969: 203).

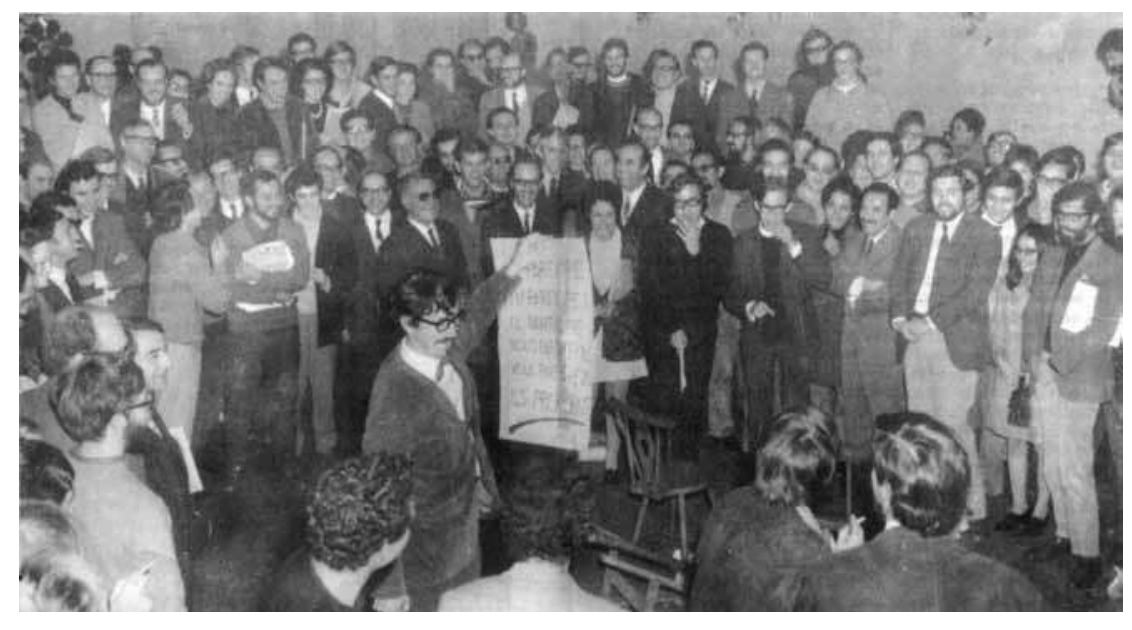

Encontro de 1969

(C) Ordem dos Arquitectos, Jornal Arquitectos, n. ${ }^{\circ}$, Fev. 1982, p. 8-9

O folheto de divulgação dos resultados do Encontro nada diz sobre o desenrolar dos trabalhos, apenas apresenta fotografias de mesas repletas e salas cheias (Comissão Organizadora, 1969b). De forma discreta, sem destaque ou título, na continuidade das conclusões dos temas, é publicado o manifesto assinado por estudantes e assalariados - a comissão organizadora não ignorava o sucedido, mas optava por não lhe dar relevância.

A revista Arquitectura dispensa a descrição dos acontecimentos em favor de depoimentos, mas comenta que os 45 participantes no manifesto apresentado durante o Encontro deveriam contribuir para a "vitalização de um corpo profissional que - forçoso é verificá-lo - continua à procura da sua vocação" (Duarte, 1969: 201). Nenhum dos depoimentos publicados é da autoria de subscritores deste manifesto, porque não responderam ao convite para o fazerem.

Dos 273 participantes inscritos no Encontro, 139 são arquitectos e 129 são estagiários e estudantes de arquitectura, aos quais se acrescenta um número não determinado de assistentes não inscritos. Uma assembleia constituída 
por quase tantos não arquitectos como por aqueles que o eram, poderá por si só explicar a repercussão da sua participação.

"[...] 'O Encontro foi inédito pelo desencontro de gerações' - exclamava-se à saída da última sessão" num confronto despoletado pelos estagiários e estudantes (apud Duarte, 1969: 202).

Nascidos após 1940, estes estudantes frequentaram as Belas-Artes já no decurso da década de 60, participando na contestação à estrutura curricular do curso de arquitectura e nas sucessivas crises académicas (1962, 1965 e 1969). Movimento de contestação que se foi generalizando e politizando ao longo dos anos (Benamor, 1996: 644-645).

Muitos dos jovens arquitectos e estudantes de arquitectura participam ou identificam-se com os novos sectores de oposição, da extrema-esquerda aos católicos progressistas, revendo-se na sua leitura da sociedade e em particular na oposição à guerra colonial. ${ }^{14}$ Também não lhes era estranha a sua forma de intervenção. É esse contexto mais vasto de contestação que se revela através do abaixo-assinado e de duas outras manifestações com carácter panfletário e individualizado, como o provocatório "manifesto" assinado por "Miguel" (Miguel, 1969) ou a encenação de destruição dos objectos-fetiche do arquitecto (Bandeirinha, 2007: 89).

O Abaixo-assinado (1969) distribuído no início do Encontro proclamava o fim da unidade profissional, a existência de grupos e diferentes interesses cuja identificação era necessária para a resolução dos problemas profissionais. Entre estudantes e estagiários havia o entendimento de que as diferenças existentes entre arquitectos impediam um discurso unitário nos moldes tradicionais da vida do Sindicato. ${ }^{15}$ Mais do que ruptura, era uma afirmação de princípio. Porque não enunciava oposição à realização do Encontro, discordância com os temas de debate, nem o afastamento do Sindicato, mas sim outra forma de participação. Mais do que o antagonismo de classes de pendor marxista que se depreendia da formulação do texto, um ano após o Maio de 1968 estamos perante uma afirmação geracional (Rotman, 2009: 126).

Será nos depoimentos publicados na revista Arquitectura que este "desencontro" ficará registado. Por parte dos arquitectos mais jovens é manifesto o esforço de compreensão do sucedido, lançando pistas para a sua interpretação. "O 'vazio', percepção da desestruturação da classe, não significa ruptura e muito menos ‘dépassement' de uma situação”, afirma Guilherme

\footnotetext{
${ }^{14}$ Os estudantes são especialmente sensíveis à questão da guerra colonial por a incorporação ser imediata em caso de reprovação durante o curso ou após a conclusão da licenciatura.

${ }_{15}$ Entrevista de Nicolau Brandão a João Afonso sobre a situação no ensino da arquitectura na década de sessenta, em 27 de Novembro de 2009.
} 
Câncio Martins (apud Duarte, 1969: 202). Já para os arquitectos de gerações anteriores, como Nuno Teotónio Pereira ou Francisco Keil do Amaral, esta mudança foi desvalorizada ou representou o enfraquecimento dos arquitectos. Para o primeiro, a polémica de carácter intraprofissional não teve consequência nos resultados alcançados ${ }^{16}$ No entanto, para Keil, apesar de ter feito "a equação perfeita" do problema levantado pelos contestatários, ${ }^{17}$ o Encontro foi uma desilusão, pois "abria perspectivas para uma contestação de grande estilo; ampla, idealista, esclarecida, ... e pariu diversas pequenas contestações sectoriais desnecessárias, de contestação porque sim - o que foi pena." (Keil apud Duarte, 1969: 202).

Neste sentido, o Encontro é atravessado por dois discursos políticos, um consensual em torno da necessidade de transformação do sistema político e social, outro em que se acentuam antagonismos acerca da forma de o olhar e nele intervir. É este último debate entre gerações - jovens não arquitectos versus arquitectos profissionais - que provoca o confronto, ou o desencontro que marca esta reunião.

\section{Conclusão}

A sociedade portuguesa estava em mudança, o debate político já não se cingia ao período eleitoral, ultrapassava as fronteiras das estruturas organizadas para o efeito e estendia-se à sociedade.

O debate político esteve sempre subjacente às grandes reuniões do Sindicato, mas foram as eleições legislativas de 1969, o seu sucesso na mobilização e o desaire nos resultados que propiciaram a organização e o ambiente vivido no Encontro Nacional de Arquitectos. Os seus participantes trouxeram para o debate profissional a vontade de mudança, questionando qual o possível contributo da arquitectura; mas também as divisões políticas e a fractura geracional exposta por Maio de 68. Tudo isso foi o Encontro.

Para os arquitectos, o Encontro é o culminar de um percurso de tomada de consciência da sociedade, iniciado no congresso de 1948 e consolidado nas reuniões de 1957 e 1966. No I Congresso esteve em causa a autonomia da profissão face ao regime; na I Reunião de Arquitectos, a criação da identidade unificadora de uma classe perante a sociedade; na II Reunião Geral de Arquitectos debateram-se as regras a partilhar, que permitiriam melhor intervir na sociedade.

\footnotetext{
${ }^{16}$ Entrevista de Nuno Teotónio Pereira a João Afonso sobre o Encontro Nacional de Arquitectos, em 15 de Janeiro de 2010.

${ }^{17}$ Entrevista de Nicolau Brandão a João Afonso sobre a situação no ensino da arquitectura na década de sessenta, em 27 de Novembro de 2009.
} 
Em 1969, o debate em torno da profissão estava realizado e os seus valores colectivamente adquiridos. Os arquitectos, por um lado, viram-se para a sociedade querendo nela intervir; já não se trata de defender o espaço da arquitectura, mas, com o seu saber, contribuir para a sua transformação. Por outro lado, a salvaguarda da identidade colectiva já não exige o consenso, dando lugar à diversidade de pensamento e formas de actuar; a unidade profissional deixou de ser considerada necessária e a acção individualizou-se.

A transformação no seio da profissão, bem como o debate em torno dela, podem ser deduzidos do panorama sociopolítico, da viragem do discurso unitário para um debate plural e diversificado. Até ao 25 de Abril de 1974, a intervenção social dos arquitectos no âmbito disciplinar será delineada segundo correntes de opinião, grupos relativamente restritos que preconizam determinadas formas de acção em campos específicos da actividade social e profissional.

No Encontro poderá estar a chave para compreender, por um lado, a matriz de identificação da profissão de arquitecto em Portugal, entre os valores disciplinares em comum e a diversidade de olhares para a sociedade. $\mathrm{E}$, por outro lado, a resposta à questão contemporânea de qual o papel político da profissão e dos limites para o debate político no seio profissional.

\section{Referências bibliográficas}

Abaixo-assinado ao Encontro Nacional dos Arquitectos (1969), Lisboa, Arquivo Nuno Teotónio Pereira, Pasta 19.

Bandeirinha, José António (2007), O Processo SAAL e a Arquitectura no 25 de Abril de 1974. Coimbra: Imprensa da Universidade de Coimbra.

Benamor, Marta Duarte (1996), "Movimentos Estudantis", in Fernando Rosas e José Maria Brandão de Brito (direcção), Dicionário de História do Estado Novo, II. Venda Nova: Bertrand Editora, 640-645.

Brito, José Maria Brandão de; Rollo, Maria Fernanda (1996), "Congressos e exposições industriais”, in Fernando Rosas e José Maria Brandão de Brito (direcção), Dicionário de História do Estado Novo, II. Venda Nova: Bertrand Editora, 192-195.

Cervelló, Josep Sanchez (2010), "A República reencontra os seus cidadãos: as oposições, da guerra colonial ao 25 de Abril de 1974", in Manuel Loff e Teresa Siza (coord. cient.), Resistência: da alternativa republicana à luta contra a ditadura. Lisboa, Imprensa Nacional - Casa da Moeda, 95-102.

Comissão Organizadora (1969a), Anúncio do Encontro Nacional de Arquitectos de 6 de Novembro de 1969. Lisboa, Arquivo Nuno Teotónio Pereira, Pasta 19.

Comissão Organizadora (1969b), Folheto de divulgação O Encontro Nacional de Arquitectos. Lisboa, Arquivo Nuno Teotónio Pereira, Pasta 19. 
Direcção (1957), Circular 14/24, de 30 de Julbo de 1957. Lisboa: S.N.A., Arquivo OA. Direcção (1966), Circular 7/33, de Janeiro de 1966. Lisboa: S.N.A., Arquivo OA.

Direcção (1969), Circular 22/36, de 20 de Novembro de 1969. Lisboa: S.N.A., Arquivo NTP, Pasta 19.

Duarte, Carlos (1969), “Encontro Nacional de Arquitectos Dezembro 1969”, Arquitectura, 110, Julho-Agosto, 200-207.

Duarte, Carlos (2006), “1961/1974 L’Ouverture néo-capitaliste”, L'Architecture d'Aujourd'bui, 185, Mai/Juin 1976, 22-23. [2ª ed.; 1976].

Guimarães, Fernando Peres et al., (1969), Relatório e contas de gerência. Parecer da Comissão Revisora de Contas, Março de 1969. Lisboa: S.N.A., policopiado, FAUP/ CDUA/ AL-CB/ SIND/ 295.

Martins, Artur Pires et al. (1969), O SNA ou uma associação livre de arquitectos. Lisboa, Arquivo Nuno Teotónio Pereira, Pasta 19.

Miguel (1969), Manifesto, 8 de Dezembro de 1969, Arquivo Nuno Teotónio Pereira, Pasta 19.

Pereira, Nuno Teotónio (1969), Participação popular e trabalbo do arquitecto. Lisboa, Arquivo NTP, Pasta 19.

Pereira, Nuno Teotónio (1996), "O Colóquio de Habitação", in Escritos (1947-1996, selecção). Porto: FAUP publicações, 98-105.

Pimentel, Irene Flunser (2007), A bistória da PIDE. Rio de Mouro: Círculo de Leitores/ Tema e Debates.

Raby, Linda Dawn (1988), A resistência antifascista em Portugal-comunistas, democratas e militares em oposição a Salazar, 1941-1974. Lisboa: Edições Salamandra, Lda.

Ribeiro, Ana Isabel (2008), "Relembrando o Congresso de 48”, in Ana Tostões (coord.), $1^{\circ}$ Congresso Nacional de Arquitectura. Lisboa: Ordem dos Arquitectos, 23-33 [2 ${ }^{\mathrm{a}} \mathrm{ed}$. Fac-similada; 1948].

Rodrigues, Maria de Lourdes; Pereira, Sandra (1996), "Congressos de Engenharia”, in Fernando Rosas e José Maria Brandão de Brito (direcção), Dicionário de História do Estado Novo, II. Venda Nova: Bertrand Editora, 186-188.

Rosas, Fernando (2004), Portugal Século XX (1890-1976), Pensamento e Acção Política. Lisboa: Editorial Notícias.

Rotman, Patrick (2009), Maio de 68 explicado àqueles que o não viveram. Lisboa: Guimarães Editores, SA.

S.N.A. (1934), Livro de Actos de Posse. Lisboa: Arquivo Ordem dos Arquitectos.

S.N.A. (1948), $1^{\circ}$ Congresso Nacional de Arquitectura - Relatório da Comissão executiva, Teses, Conclusões e votos do Congresso. Lisboa: Sindicato Nacional dos Arquitectos. Soares, Mário (1999), "O meu amigo Keil”, in Irisalva Moita (com. cient.), Keil do Amaral, O arquitecto e o bumanista. Lisboa: Contemporânea Editora/CML, 139-142.

Torres, Fernando et al. (1969), Comunicado n. ${ }^{\circ} 1$ do Encontro Nacional dos Arquitectos. Lisboa, Arquivo NTP, Pasta 19. 